\title{
RNA interference suppression of mucin $5 A C$ (MUC5AC) reduces the adhesive and invasive capacity of human pancreatic cancer cells
}

\author{
Sadaaki Yamazoe, Hiroaki Tanaka*, Tetsuji Sawada, Ryosuke Amano, Nobuya Yamada, Masaichi Ohira and
} Kosei Hirakawa

\begin{abstract}
Background: MUC5AC is a secretory mucin normally expressed in the surface muconous cells of stomach and bronchial tract. It has been known that MUC5AC de novo expression occurred in the invasive ductal carcinoma and pancreatic intraepithelial neoplasm with no detectable expression in normal pancreas, however, its function remains uncertain. Here, we report the impact of MUC5AC on the adhesive and invasive ability of pancreatic cancer cells.

Methods: We used two MUC5AC expressing cell lines derived from human pancreatic cancer, SW1990 and BxPC3. Small-interfering (si) RNA directed against MUC5AC were used to assess the effects of MUC5AC on invasion and adhesion of pancreas cancer cells in vitro and in vivo. We compared parental cells (SW1990 and BXPC3) with MUC5AC suppressed cells by si RNA (si-SW1990 and si-BxPC3).

Results: MUC5AC was found to express in more than $80 \%$ of pancreatic ductal carcinoma specimens. Next we observed that both of si-SW1990 and si-BXPC3 showed significantly lower adhesion and invasion to extracellular matrix components compared with parental cell lines. Expression of genes associated with adhesion and invasion including several integerins, matrix metalloproteinase (MMP) -3 and vascular endothelial growth factor (VEGF) were downregulated in both MUC5AC suppressed cells. Furthermore, production of VEGF and phosphorylation of VEGFR-1 were significantly reduced by MUC5AC down regulation. Both of si-SW1990 and si-BXPC3 attenuated activation of Erk1/2. In vivo, si-SW1990 did not establish subcutaneous tumor in nude mice.
\end{abstract}

Conclusions: Knockdown of MUC5AC reduced the ability of pancreatic cancer cells to adhesion and invasion, suggesting that MUC5AC might contribute to the invasive motility of pancreatic cancer cells by enhancing the expression of integrins, MMP-3, VEGF and activating Erk pathway.

\section{Background}

Pancreatic cancer has a poor prognosis; the 5-year survival rate in only $3 \%$ and the median survival rate is only 6 months[1]. It is also associated with aggressive cancer cells, and metastatic disease that results from a lack of early-stage diagnostic methods and effective therapies. Adhesiveness and invasiveness of cancer cells play a central role in pancreatic cancer progression [2,3]. Mucins are highly glycosylated glycoproteins that are the major components of the viscous mucous gel covering the surface of epithelial tissues [4]. Changes in mucin expression

* Correspondence: hiroakitan@med.osaka-cu.ac.jp

1 Department of Surgical Oncology, Osaka City University Graduate School of Medicine, Osaka, Japan

Full list of author information is available at the end of the article or glycosylation accompany the development of cancer and influence cellular growth, differentiation, transformation, adhesion, invasion and immune surveillance [5]. Several papers have described the relationship between mucin and pancreatic cancer, for example, de novo expression of MUC5AC frequently occurs in intraductal papillary mucinous tumors and pancreatic adenocarcinoma [6-8], while Takikita et al. reported that borderline statistically significant associations are seen between expression of MUC5AC and shorter survival time in patients with pancreatic cancer [8]. However, the function of MUC5AC remains uncertain. In this study, we examined the impact of MUC5AC in a human pancreatic cancer cell line. 
Small interfering RNA has recently been developed as a powerful tool to suppress the expression of specific gene products [9-11]. Previous studies on MUC1 suppression [10-12] in lung, breast and pancreatic cancer cells reported increased sensitivity to genotoxic drugs both in vitro and in vivo [11]. We down-regulated MUC5AC expression by siRNA and investigated the effects on the malignant and metastatic potential of human pancreatic cancer cell lines, SW1990 and BxPC3.

\section{Methods}

\section{Cell lines and culture conditions}

The human pancreatic cancer cell lines of SW1990, BxPC3 and PCI-64 were cultured in Dulbecco's modified Eagle's medium containing $10 \%$ fetal bovine serum, as described previously [13]. The stable cell line si-SW1990 and si-BxPC3, created by siRNA transfection of parental cells respectively, was maintained in the above medium containing $500 \mu \mathrm{g} / \mathrm{ml}$ Geneticin (Invitrogen Japan, Tokyo, JAPAN). Cells were cultured at $37^{\circ} \mathrm{C}$ under $5 \% \mathrm{CO} 2$ in incubators with $100 \%$ humidity.

\section{Immunohistochemistry}

Paraffin-embedded specimens from 100 patients with pancreatic ductal carcinoma who underwent resection at Department of Surgical Oncology, Osaka City University Hospital from 1995 to 2007 were stained with antiMUC5AC monoclonal antibody (abcam, USA) according to the manufacture's protocol.

\section{siRNA design}

The design of 19 nucleotide target sequences were based on a computer algorithm and 5'-GCCACCGCTGCGGCCTTCTTC-3' was selected as the target sequence. These were separated by a nine-nucleotide noncomplementary spacer (5'-TTCAAGAGA-3') from the reverse complement of the same 19-nucleotide sequence.

For preparation of recombinant plasmids, oligonucleotides $(64 \mathrm{bp})$ were ligated into the mammalian expression vector, pSilencer 3.1-H1 neo (Applied Biosytems Japan, Tokyo, JAPAN) at the BamHI and HindIII cloning sites. Recombinant MUC5AC-pSUPER gfp-neo constructs were used to transform Escherichia coli DH5, which were selected on ampicillin-agarose plates and verified by sequencing.

\section{Cell proliferation assay}

Cell proliferation was determined by the ${ }^{3} \mathrm{H}$-thymidine uptake assay. After $24 \mathrm{~h}$ or $48 \mathrm{~h}$ of incubation, radioactivity was measured using cell harvester and counters. Experiments were performed in triplicate, and values are expressed as cpm/well.

\section{Adhesion assay}

The adhesion assay was done as described before [14]. Briefly, A 96-well microtiter plate was coated with Matri- gel $(2 \mu \mathrm{g} /$ well $)$, laminin $(4 \mu \mathrm{g} /$ well $)$ and fibronectin $(4 \mu \mathrm{g} /$ well). Cancer cells $\left(4 \times 10^{5}\right)$ were then seeded onto these components. No chemicals for extracellular stimulation were added. Cells were allowed to adhere to each well for $30 \mathrm{~min}$ at $37^{\circ} \mathrm{C}$ and were then gently washed three times with PBS. The adhesive cancer cells to extracellular components were evaluated by 3-(4, 5-dimethylthiazol-2-yl)2, 5-diphenyl-tetrazolium bromide colorimetric assay (MTT assay). The percentage of cells adhering was calculated as follows: \% binding = (absorbance of treated surface - ECM component)/absorbance of total surface $x$ 100. All experiments were performed in triplicate.

\section{Invasion assay}

Invasion activity of cancer cells was measured by the method of Albini et al. [15] with some modifications. Briefly, cancer cells $\left(1 \times 10^{4} / \mathrm{ml}, 200 \mu \mathrm{l}\right)$ were seeded in the upper chamber separated with a $12-\mu \mathrm{m}$ membrane filter coated with $50 \mu \mathrm{g}$ of Matrigel without adding extracellular stimuli. After incubation for $72 \mathrm{~h}$ at $37^{\circ} \mathrm{C}$, cancer cells invading the lower chamber were manually counted under a microscope. Six randomly selected fields were counted for each assay. Mean values from six fields were calculated as sample values. For each group, culture was performed in triplicate.

\section{RNA isolation and reverse transcription-polymerase chain reaction (RT-PCR)}

Total RNA extraction and cDNA amplification were as described previously [16]. The following oligonucleotides were used for RT-PCR analysis: MUC5AC: 5'-TGCACCTGTGACAGCAGGAT-3' (sense), 5'-ACCTCCACCTTCCTATGGCT-3' (anti-sense); integrin $\alpha 3$ : 5'TACGTGCGAGGCAATGACCTA-3' (sense), 5'-TTTGGGGGTGCAGGATGAAGCT-3' (anti-sense); integrin 9: 5'-AGAGGAGGAGAGGGAACTGC-3' (sense), 5'CCCAGACAGGTGGCTTGTAT-3' (anti-sense); integrin ß3: 5'-GGGGACTGCCTGTGTGACTC-3' (sense), 5'CTTTTCGGTCGTGGATGGTG-3' (anti-sense); MMP3: 5'-GATATAAATGGCATTCAGTCCCTC-3' (sense), 5'-TCCTTGCTAGTAACTTCATATGCG-3' (anti-sense); and VEGF: 5'-CCTGGTGGACATCTTCCAGGAGTACC-3' (sense), 5'-GAAGCTCATCTCTCCTATGTGCTGGC-3'(anti-sense). The PCR condition as follows: predenaturation, $94^{\circ} \mathrm{C}$ for $10 \mathrm{~min}$, denaturation, $94^{\circ} \mathrm{C}$ for $50 \mathrm{sec}$, annealing, $59^{\circ} \mathrm{C}$ for $50 \mathrm{sec}$; extention, $72^{\circ} \mathrm{C}$ for 1 min and final incubation, $72^{\circ} \mathrm{C}$ for $7 \mathrm{~min}$. Other primers and PCR conditions were as described previously [16-19].

\section{In vivo experiments}

For subcutaneous tumorigenicity, $1 \times 10^{7}$ cancer cells were injected into the flanks of BALB/c nude mice. For in vivo liver metastasis, $7.5 \times 10^{5}$ cancer cells were injected into the lower pole of the spleen under ether anesthesia. Mice were sacrificed after 5 weeks in order to measure the number of metastatic tumors in the liver. For in vivo 
peritoneal dissemination, $1 \times 10^{7}$ each cancer cells were injected into the peritoneal cavity, and the formation of peritoneal metastases was examined. Mice were sacrificed 14 days after injection, and peritoneal metastatic nodules were counted.

Animal studies were performed in accordance with the standard guidelines established by the Osaka City University Graduate School of Medicine. Six-week-old female Balb/c nude mice (Oriental Kobo, Tokyo, JAPAN) were used in all experiments, and five mice were used in each group.

\section{Measurement of VEGF in cell culture supernatants}

For the generation of conditioned media, $1 \times 10^{5}$ cells were plated in a 6-well plate in growth medium and were allowed to attach overnight at $37^{\circ} \mathrm{C}$. After washing with PBS, cells were moved to serum-free medium. After $24 \mathrm{~h}$ of incubation, conditioned medium was collected and VEGF concentrations were determined using a commercial human VEGF-specific enzyme-linked immunosorbent assay (R\&D Systems, USA).

\section{Western blot analysis}

Protein expression of VEGFR1, p-VEGFR1, MMP-3, Erk1/2, p-ERK and alpha3-integrin was examined by Western analysis. Cells grown to semiconfluence in 100$\mathrm{mm}$ dishes were lysed in lysis buffer containing $20 \mathrm{mM}$ Tris (pH 8.0), $137 \mathrm{mM}$ EDTA, $100 \mathrm{mM} \mathrm{NaF}, 1 \mathrm{mM}$ phenylmethylsulfonyl fluoride, 0.25 trypsin inhibitory units/ $\mathrm{ml}$ aprotinin and $10 \mathrm{mg} / \mathrm{ml}$ leupeptin. Aliquots containing $50 \mu \mathrm{g}$ of total protein were subjected to SDS-PAGE, and the protein bands were transferred to a polyvinylidene difluoride membrane (Amersham, Aylesbury, UK). Membranes were blocked with $5 \%$ nonfat milk or 5\% FBS in Tris-buffered saline containing 0.1\% Tween 20 at room temperature for $1 \mathrm{~h}$ and then incubated overnight at $4^{\circ} \mathrm{C}$ with mouse antihuman VEGF R1 antibody, rabbit anti-phospho-VEGF R1 antibody (R\&D systems), mouse anti-MMP3 monoclonal antibody (MILLIPORE, USA), rabbit Erk1/2 polyclonal antibody, mouse p-ERK monoclonal antibody (SANTA CRUZ, USA), rabbit antihuman integrin alpha3 polyclonal antibody (MILLIPORE, USA) and beta-actin antibody (Cell Signaling, USA). After three washes, membranes were incubated for $1 \mathrm{~h}$ at room temperature with anti-mouse or rabbit IgG horseradish peroxidase-linked species-specific whole antibody (Amersham, USA). The three washes in TBST were repeated, and then the immunoreactive protein was detected using ImmunoStar Long Detection (WAKO, Tokyo, JAPAN).

\section{Statistical analysis}

Student's t-test was used for statistical analysis. P values of less than 0.05 were considered to indicate statistical significance.

\section{Results}

Reduced expression of MUC5AC in SW1990 and BxPC3 cells As Background, we tested MUC5AC expression in 100 specimens of pancreatic ductal carcinoma (Fig. 1). MUC5AC protein was detected in $85 \%$ of patients with pancreatic cancer, whereas no expression was observed in normal ductal tubular cells. Then, to examine the function of MUC5AC in pancreatic cancer cells, we delivered siRNA vector targeting MUC5AC into two human pancreatic cancer cells SW1990 and BxPC3 which were expressed MUC5AC. The resulting stable cell line, siSW1990 and si-BxPC3, exhibited no expression of MUC5AC mRNA (Fig. 2A). As negative control, we confirmed no MUC5AC expression in PCI-64 cell (Fig. 2A). Also MUC5AC siRNA had no effect on the viability and form of SW1990 as well as BxPC3. The proliferative properties of transfectants did not differ from those of the parental cell lines (Fig. 2B). Doubling time of both cell lines were about 13 hours.

\section{Suppression of MUC5AC reduced the adhesive and invasive capacity of SW1990 and BxPC3 cells}

Cancers grow through adhesion or invasion into interstitial tissue via extracellular matrix components (ECM). Then, we compared these properties between parental cell lines and siRNA transfectants (si-SW1990, si-BxPC3). We examined cellular adhesiveness to representative ECM of Matrigel, laminine and fibronectin, and evaluated cell viability si-SW1990 or si-BxPC3 adhering to ECM. The number of viable si-SW1990 was significantly reduced when compared with SW1990 (Fig. 3A). The percentage of adhesion to Matrigel, laminin and fibronectin decreased by $29 \%(\mathrm{P}=0.019), 22 \%(\mathrm{P}=0.008)$ and $34 \%$ $(\mathrm{P}=0.0002)$, respectively (Fig. $3 \mathrm{~B})$. si-BxPC3 also

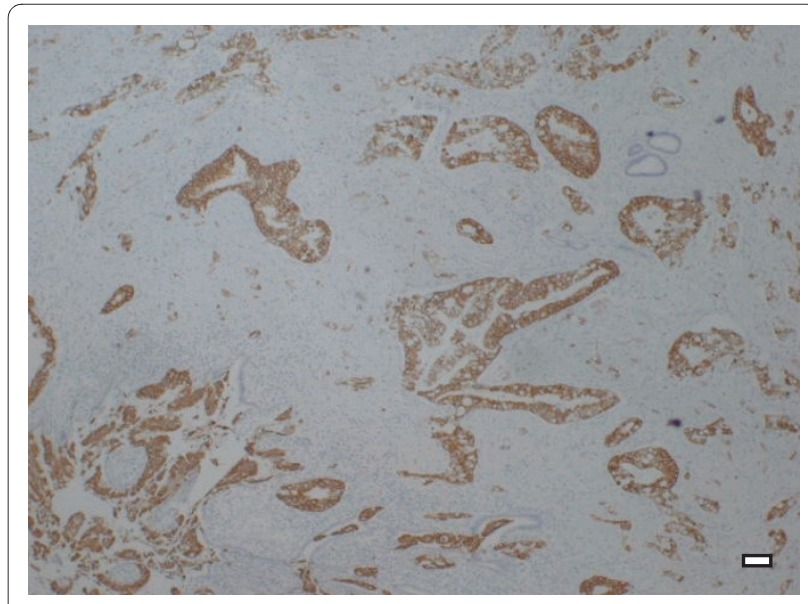

Figure 1 Immunohistochemistry of MUC5AC. Paraffiin-embedded tissues were stained using MUC5AC monoclonal antibody. Representative fileld of tumor tissue among 100 specimens of pancreatic ductal carcinoma showed MUC5AC protein expression (brown) limited to tumor epithelium. Scale bar, 50 rm. 


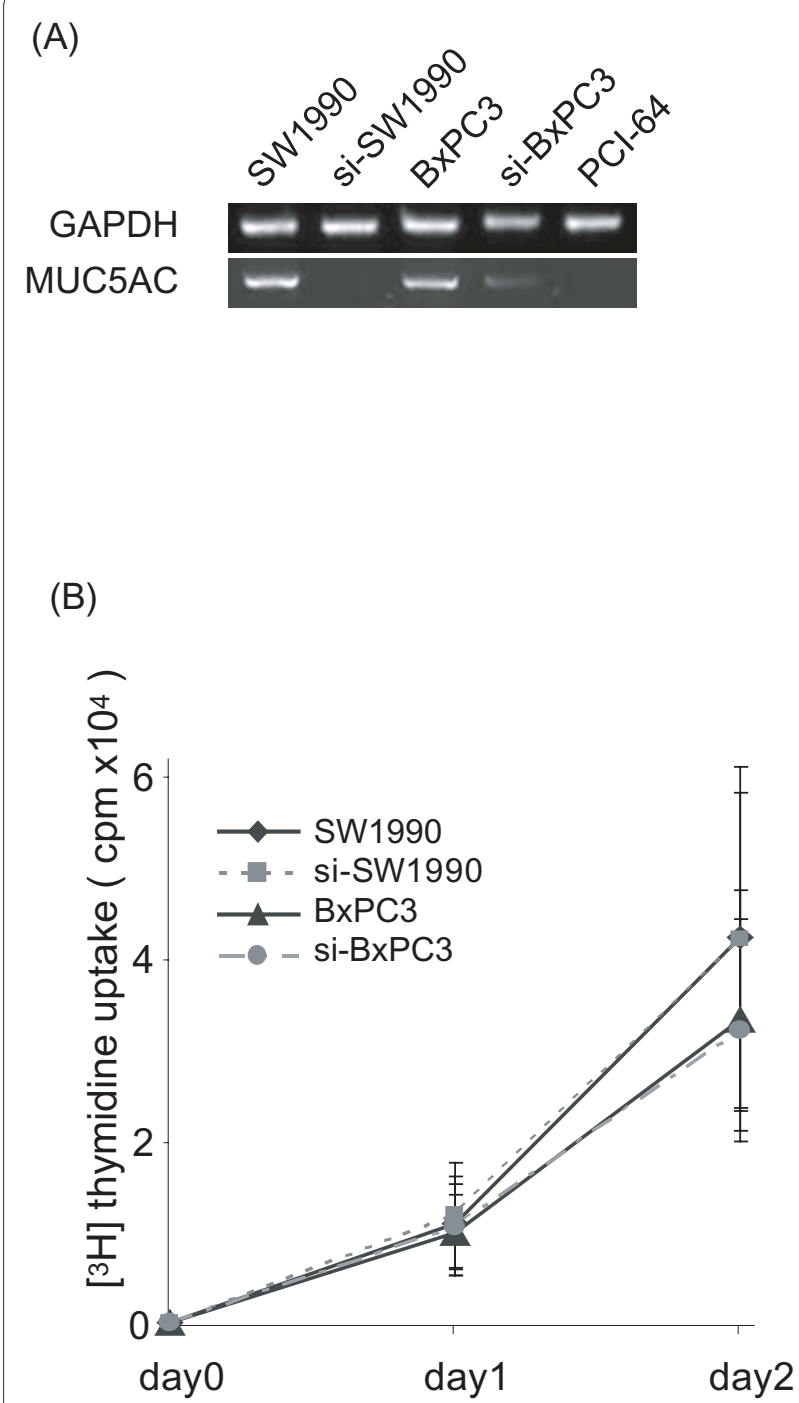

Figure 2 Effect of si-RNA transfection on parental cells. (A) Proliferation assay. Cell proliferation was measured by the $\left[{ }^{3} \mathrm{H}\right]$ thymidine uptake assay after $24 \mathrm{~h}$ or $48 \mathrm{~h}$ of incubation. Proliferation curve was plotted as radioactivity versus incubation time of cancer cells. No differences in proliferation were seen between si-SW1990 and p-SW1990. Shown data are means \pm SD. (B) Detection of MUC5AC mRNA by RTPCR. mRNA expression of MUC5AC decreased in si-SW1990 and siBxPC3 compared with parental cells. PCI-64 has no MUC5AC endogeneously.

revealed decrease of adhesion to three ECMs compared with BxPC3 (Fig. 3B). We then evaluated the invasive activity of cancer cells by Matrigel invasion assay. Through the $12-\mu \mathrm{m}$ pore membrane, the number of migratory si-SW 1990 cells significantly decreased by $85 \%$ compared with SW1990 (Fig. 4A, B). si-BxPC3 showed similar reduction of invasion to ECMs (Fig. 4B).

\section{Suppression of MUC5AC reduced expression of integrins and production of MMP-3 and VEGF}

In order to clarify the underlying mechanisms of these properties, we examined the mRNA expression of mole-

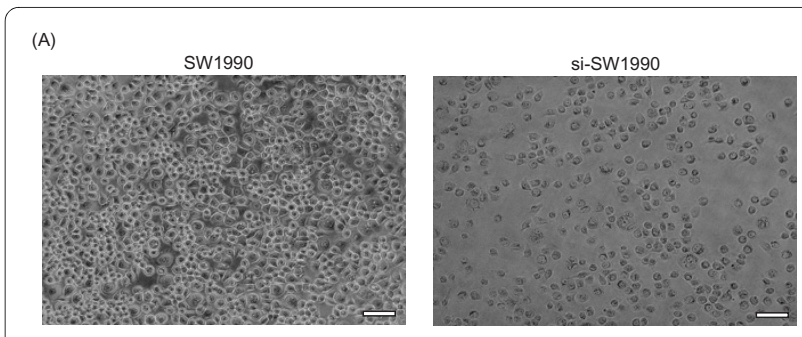

(B)

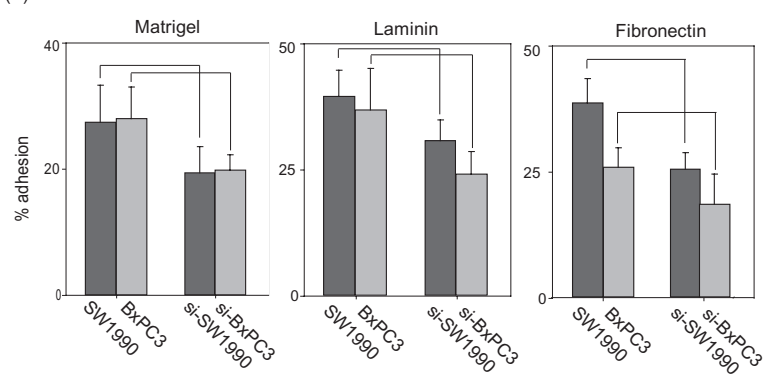

Figure 3 Effect of MUC5AC suppression on cell adhesion. (A) Cancer cells were seeded in 96-well plates coated with Matrigel, laminin and fibronectin. After 30 min incubation, adherent cells were quantified by MTT assay. A phase contrast photograph of SW-1990 shows the representative adhering cells to the well coated in finbonectin. Scale bar, $50 \mu \mathrm{m}$. (B) Quantitication of the effect of MUC5AC downregulation on cell adhesion to Matrigel, laminin and fibronectin. Cell adhesion of si-SW1990 and si-BXPC3 to ECM declined significantly compared with parental cells. Shown data are means \pm SD. ${ }^{*} ; \mathrm{P}<0.05 ;{ }^{* *} ; \mathrm{P}<0.01$; ${ }^{* * *}$; $\mathrm{P}<0.001$.

cules associated with cell adhesion and invasion by RTPCR. No differences were seen between SW1990 and siSW1990 with regard to mRNA expression of E-Cadherin, Snail, ZO-1, ZO-2, MMPs and integrins, whereas mRNA expression levels of $\alpha 3, \alpha 9$, and $\beta 3$ integrin, MMP- 3 and VEGF had decreased in both of si-SW1990 as compared with SW1990. si-BxPC3 also exhibited lower mRNA expression of $\alpha 3$ integrin, MMP-3 and VEGF. No expression of VEGFR-2 and twist were detected (Fig. 5A). Next, we investigated production of MMP-3 and alpha 3-integrin proteins by cancer cells, resulting in higher expression level of these proteins by parental cells compared with MUC5AC suppressed cells (Fig. 5B). In addition, production of VEGF was significantly lower in the culture supernatant of si-SW1990 and si-BxPC3 (Fig. 5C). Having demonstrated that SW1990 and si-SW1990 cell express VEGFR-1 mRNA and produce VEGF, we finally examined phosphorylation of VEGFR-1 (p-VEGFR-1) and Erk $1 / 2$ on both cell lines by western blot analysis. Fig. 5B showed that VEGF induced VEGFR-1 phosphorylation were higher in both of SW1990 and BxPC3 compared with si-SW1990 and si-BxPC3. Moreover, Erk 1/2 phosphorylation was strongly reduced in MUC5AC reducing cells. On the other hand, PCI-64 which has originally expression of MUC5AC did not show mRNA expression 

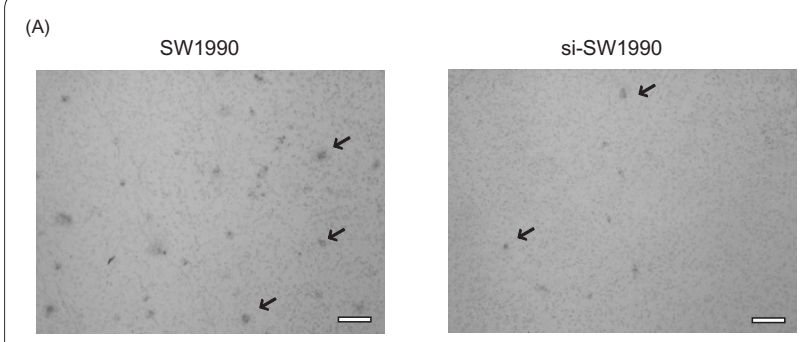

(B)

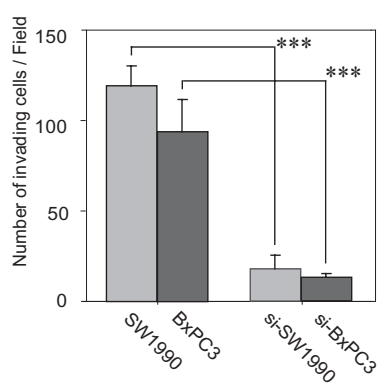

Figure 4 Effect of MUC5AC suppression on cell invasion. (A) Cell invasion through membrane filter coated with Matrigel was examined. $72 \mathrm{~h}$ later, invading cancer cells were stained by hematoxylin and counted under a microscope. A phase contrast photograph of SW1990 shows the representative adhering cells to the well coated in finbonectin (arrows). Scale bar, $50 \mu \mathrm{m}$. (B) The number of invading siSW1990 and si-BXPC3 was significantly lower compared to parental cells. Data shown are means \pm SD. ${ }^{* * *} ; P<0.001$.

of genes up-regulated in SW1990 and BxPC3 or the phosphorylation of VEGF-R or Erk1/2. No activation of Akt signaling was detected (data not shown).

\section{Effects of MUC5AC inhibition on si-SW1990 cell in vivo}

In order to evaluate in vivo effects, we examined subcutaneous tumorigenicity, liver metastasis and peritoneal dissemination. Mice receiving inoculation of si-SW1990 cells showed no subcutaneous tumorigenesis $(0 \%, 0 / 5)$, liver metastasis $(0 \%, 0 / 5)$ or mesentery metastasis $(0 \%, 0 /$ 5). In contrast, these metastases were seen in all mice inoculated with SW1990 (Fig. 6). As si-SW1990, inoculation of si-BxPC3 did not establish subcutaneous xenografts in vivo.

\section{Discussion}

In this study, we have demonstrated that suppression of MUC5AC which was commonly expressed in pancreatic ductal carcinoma reduced adhesive, invasive and metastatic potential of pancreatic cancer cell lines. These results indicated that MUC5AC expression in cancer cells might be associated with invasive progression of pancreatic ductal carcinoma. It has been reported that mucins are associated with cancer growth. For example, MUC1 and MUC4 mucin augment cellular proliferation in vivo
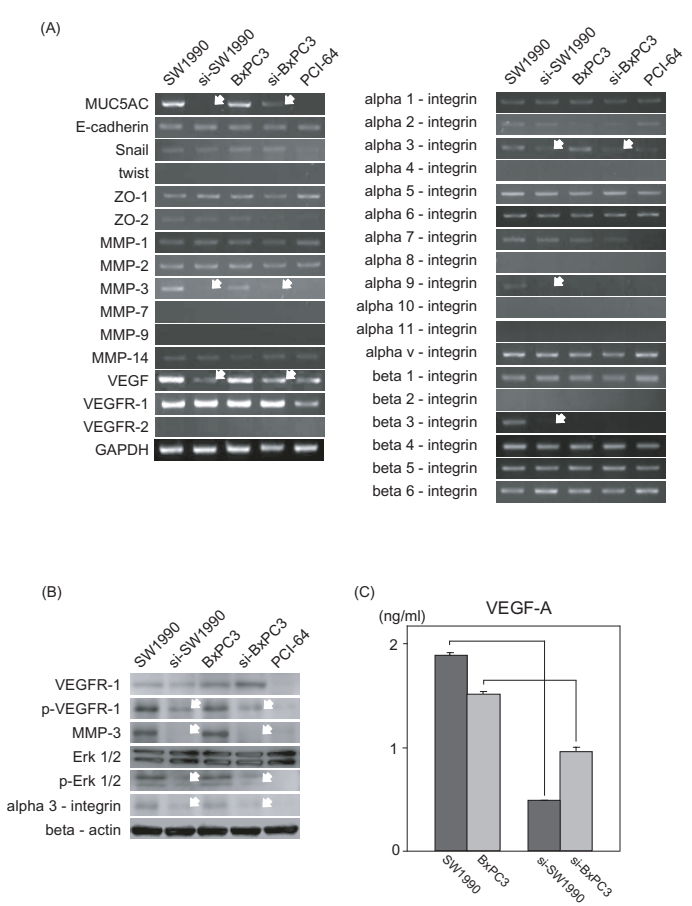

Figure 5 mRNA and protein expression profiles of cancer cell lines. (A) mRNA expression profile of cell lines. mRNA associated with cell adhesion and invasion was determined by RT-PCR. $\alpha 3, a 9$ and $\beta 3$ integrin, MMP-3 and VEGF mRNA expression (white arrows) of siSW1990 was down-regulated, as compared to SW1990. MMP-3, VEGF, and a3-integrin were decreased in si-BxPC3.PCI-64 which expressed no MUC5AC did not reveal MMP-3, a3-integrin mRNA expression. (B) Western blotting. Reduced MMP-3 and alpha3-integrin expression in si-SW1990 and si-BxPC3 were verified by western blotting. Phosphorylation of VEGFR-1 and phosphorylation of Erk1/2 were decreased in both of si-SW1990 and si-BXPC3 compared with parental cells (white arrow). (C) ELISA. Cell culture supernatants were examined for production of VEGF-A. VEGF-A production by si-SW1990 and si-BxPC3 was significantly decreased than parental cells. Data are means \pm SD. ${ }^{* *} ; \mathrm{P}<$ 0.001 .

$[12,20]$. In our study, proliferation rate was not affected, although invasive and adhesive activities of SW1990 after MUC5AC inhibition were decreased markedly, suggesting that MUC5AC, similarly to MUC1 or MUC4, might have potential to accelerate progression of pancreatic cancer.

For cancer progression, several genes related to cell attachment, proteolysis and angiogenesis are important. We demonstrated that si-SW1990 reduced expression of $\alpha 3, \alpha 9$ and $\beta 3$ integrins and MMP-3. Another MUC5AC down-regulated BxPC3 cells also decreased MMP-3, $\alpha 3-$ integrin and VEGF. These results were supported by other reports. For example, Lohi reported that $\alpha 3 \beta 1$ integrin was a probable cell surface receptor acting with laminin-5 in the regulation of carcinoma cell invasion and proliferation [21]. $\alpha 9 \beta 1$ integrin can mediate accelerated cell migration [22] and Hosotani demonstrated that $\alpha 5 \beta 3$ 


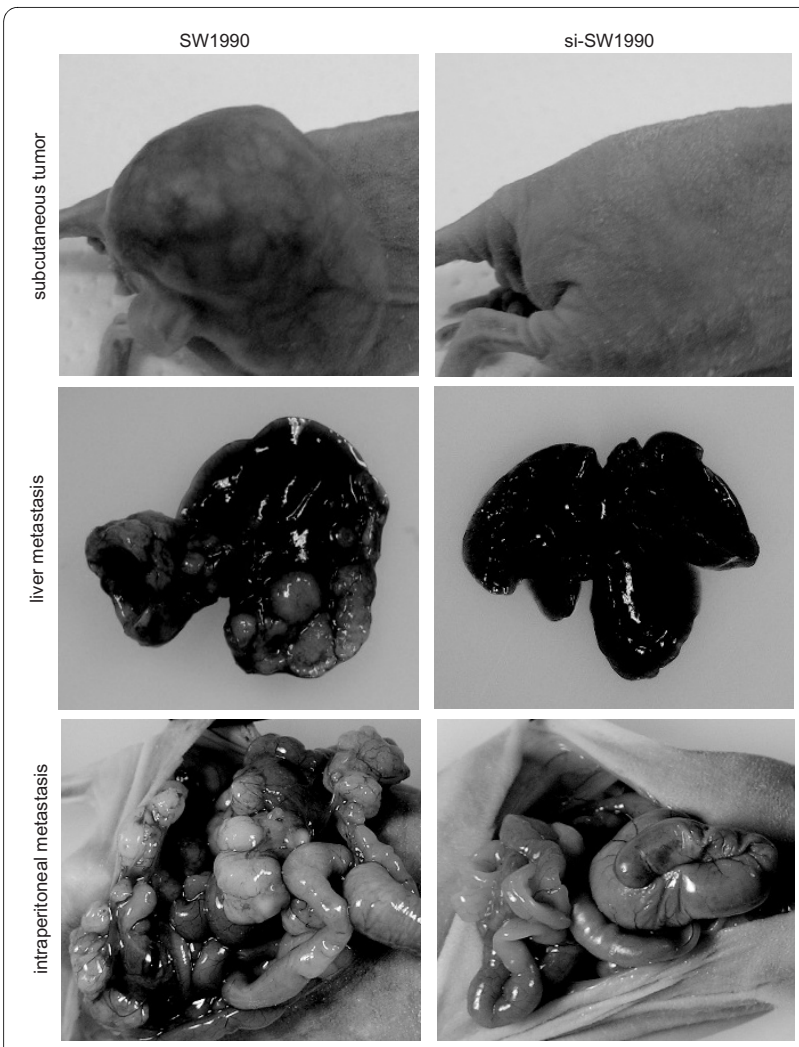

Figure 6 Effects of MUC5AC suppression on SW1990 cell metastasis in vivo. Images of subcutaneous xenograft, liver metastasis and peritoneal metastasis following inoculation of SW1990 or si-SW1990. SW-1990 but not si-SW1990 formed a large subcutaneous nodule, and numerous nodules in the liver and intraperitoneal cavity.

integrin expression is significantly correlated with lymph node metastasis and advanced stages of pancreatic cancer[23]. MMP-3 plays a crucial role in the insidious invasiveness of astrocytoma [24]. These results suggested that MUC5AC might augment malignant potential of pancreatic cancer cell such as MUC1 or MUC4. On the other hands, we found that PCI-64 cells by which MUC5AC was not originally expressed showed no augmentation of MMP-3, $\alpha 3$-integrin or VEGF, indicating that MUC5AC might not play a central role in progression of cancer like PCI-64 cells which have low level expression of MUC5AC.

Interestingly, we have observed significant decrease of VEGF-A production and VEGF-R1 phosphorylation by si-SW1990 and si-BxPC3 compared to parental cells. VEGF, a potent angiogenic mitogen, is linked to tumor growth, metastasis and poor prognosis for patients with pancreatic adenocarcinoma [25-28]. Association of VEGF with mucin has been reported. For example, immunohistochemistry of a combination of MUC1, VEGF and other two molecules was detected all ovarian cancer [29]. In non-small cell lung cancer, VEGF expres- sion and MUC1 expression were independent prognostic variables [30]. Although we could not find reports about relationship of VEGF with MUC5AC, our results suggested that MUC5AC might have potential to regulate VEGF expression by cancer cells themselves.

Several studies have shown correlation among integrin, MMP and VEGF. An association between $\alpha 5 \beta 3$ integrin and MMP-2 activation was demonstrated in melanoma and breast cancer cells [23]. Expression of MMP-3 was induced by VEGF treatment in human endothelial cells. Recent studies have demonstrated that tumors and lymphangiogenic growth factors, such as VEGF-A and VEGF$C$, induced lymphatic vessel expression of $\alpha 4 \beta 1$ integrin [31]. Our results showed that MUC5AC down regulation suppressed several integrins, MMP-3 and VEGF, indicating that down-regulated MUC5AC in pancreateic cancer might reduce production of VEGF-A resulting in suppression of integrins and MMP-3. However, our results did not demonstrate direct evidence that MMP-3 and $\alpha 3$ integrin suppressed by MUC5AC downregulation were associated with VEGF. Then we examined MAPK pathways in MUC5AC suppressed cells. Janes et al previously reported that pancreatic carcinoma cell lines expressed VEGFR-1, as well as VEGF and VEGFR-1 was capable of increasing MAPK signaling, migration, and invasion in an autocrine mechanism [32]. In this study, we have demonstrated that p-VEGFR-1 and p-Erk 1/2 of parental cells were down-regulated by MUC5AC suppressed cell lines. VEGF-A induced signaling cascade is mediated via activation of both of VEGFR-1 and VEGFR-2. We did not show phosphorylation of VEGF-R2 in this study, because SW1990 expressed no VEGFR-2 mRNA. Thus, our results suggest that MUC5AC positive pancreatic cancer cells might be activated the invasive potential via VEGFR1 signaling pathway in an autocrine manner.

To clarify effect of MUC5AC on tumor, we tried to test it using mouse model in vivo, because our in vitro study has the limitation with regard to true tumor microenvironment. However, we found no subcutaneous tumorigenesis, intraperitoneal metastasis or hepatic metastasis after inoculation of MUC5AC suppressed cells. Several studies have reported that VEGF is believed to be essential for growth and metastasis of solid malignancies in vivo $[27,33,34]$. Fukusawa et al previously reported that pancreatic tumor growth and metastasis in vivo were significantly suppressed by a soluble VEGFR chimer which binds VEGF-A with high affinity [35]. Although we showed no direct evidence that MUC5AC was associated with tumorigenesis of pancreatic tumor, it was likely that inhibition of MUC5AC might reduce VEGF production by tumor in vivo. For future study, it should be necessary to investigate the mechanism for association of MUC5AC with tumorigenesis in vivo. 


\section{Conclusions}

The present work is the first demonstration of an association of MUC5AC with pancreatic cancer cell invasion. MUC5AC might contribute to the progression of pancreatic cancer by inducing adhesiveness and invasiveness in ECM via VEGF overexpression, indicating that MUC5AC may be a potentially target in the treatment of pancreatic cancer.

\begin{abstract}
Abbreviations
MUC5AC: mucin 5AC; siRNA: small interfering RNA; MMP: matrix metalloprotease; VEGF: vascular endothelial growth factor; MUC1: mucin 1; FBS: fetal bovine serum; MTT assay: 3-(4, 5-dimethylthiazol-2-yl)-2, 5-diphenyl-tetrazolium bromide (Sigma) colorimetric assay; RT-RCR: reverse transcription-polymerase chain reaction; ELISA: enzyme-linked immunosorbent assay; ECM: extracellular matrix components; MUC4: mucin4.
\end{abstract}

\section{Competing interests}

The authors declare that they have no competing interests.

\section{Authors' contributions}

SY carried out almost all studies and performed the manuscript. HT and TS supported with design and interpretation of this study. Statistical analysis was carried out by SY and RA. NY provided and participated in ELISA. Overall supervision of the manuscript was completed by $\mathrm{KH}$. Financial correction was performed by $\mathrm{HT}$ and $\mathrm{KH}$. All authors read and approved the final manuscript.

\section{Author Details}

Department of Surgical Oncology, Osaka City University Graduate School of Medicine, Osaka, Japan

Received: 28 January 2010 Accepted: 23 May 2010

Published: 23 May 2010

\section{References}

1. Bardeesy N, DePinho RA: Pancreatic cancer biology and genetics. Nature reviews 2002, 2(12):897-909.

2. Grzesiak JJ, Ho JC, Moossa AR, Bouvet M: The integrin-extracellular matrix axis in pancreatic cancer. Pancreas 2007, 35(4):293-301.

3. Ellenrieder V, Adler G, Gress TM: Invasion and metastasis in pancreatic cancer. Ann Oncol 1999, 10(Suppl 4):46-50.

4. Kim YS, Gum J Jr, Brockhausen I: Mucin glycoproteins in neoplasia. Glycoconjugate journal 1996, 13(5):693-707.

5. Hollingsworth MA, Swanson BJ: Mucins in cancer: protection and control of the cell surface. Nature reviews 2004, 4(1):45-60.

6. Kanno A, Satoh K, Kimura K, Hirota M, Umino J, Masamune A, Satoh A, Asakura T, Egawa S, Sunamura M, et al.: The expression of MUC4 and MUC5AC is related to the biologic malignancy of intraductal papillary mucinous neoplasms of the pancreas. Pancreas 2006, 33(4):391-396.

7. Kim GE, Bae HI, Park HU, Kuan SF, Crawley SC, Ho JJ, Kim YS: Aberrant expression of MUC5AC and MUC6 gastric mucins and sialyl Tn antigen in intraepithelial neoplasms of the pancreas. Gastroenterology 2002, 123(4):1052-1060

8. Takikita M, Altekruse S, Lynch CF, Goodman MT, Hernandez BY, Green M, Cozen W, Cockburn M, Sibug Saber M, Topor M, et al: Associations between selected biomarkers and prognosis in a population-based pancreatic cancer tissue microarray. Cancer Res 2009, 69(7):2950-2955.

9. Kohlgraf KG, Gawron AJ, Higashi M, Meza JL, Burdick MD, Kitajima S, Kelly $\mathrm{DL}$, Caffrey TC, Hollingsworth MA: Contribution of the MUC1 tandem repeat and cytoplasmic tail to invasive and metastatic properties of a pancreatic cancer cell line. Cancer Res 2003, 63(16):5011-5020.

10. Mukherjee P, Tinder TL, Basu GD, Gendler SJ: MUC1 (CD227) interacts with Ick tyrosine kinase in Jurkat lymphoma cells and normal T cells. J Leukoc Biol 2005, 77(1):90-99.

11. Ren J, Agata N, Chen D, Li Y, Yu WH, Huang L, Raina D, Chen W, Kharbanda S, Kufe D: Human MUC1 carcinoma-associated protein confers resistance to genotoxic anticancer agents. Cancer Cell 2004, 5(2):163-175.
12. Tsutsumida H, Swanson BJ, Singh PK, Caffrey TC, Kitajima S, Goto M, Yonezawa S, Hollingsworth MA: RNA interference suppression of MUC1 reduces the growth rate and metastatic phenotype of human pancreatic cancer cells. Clin Cancer Res 2006, 12(10):2976-2987.

13. Kimura K, Sawada T, Komatsu M, Inoue M, Muguruma K, Nishihara T, Yamashita Y, Yamada N, Ohira M, Hirakawa K: Antitumor effect of trastuzumab for pancreatic cancer with high HER-2 expression and enhancement of effect by combined therapy with gemcitabine. Clin Cancer Res 2006, 12(16):4925-4932.

14. Nishimura S, Chung YS, Yashiro M, Inoue T, Sowa M: Role of alpha 2 beta 1- and alpha 3 beta 1-integrin in the peritoneal implantation of scirrhous gastric carcinoma. Br J Cancer 1996, 74(9):1406-1412.

15. Albini A, Iwamoto Y, Kleinman HK, Martin GR, Aaronson SA, Kozlowski JM, McEwan RN: A rapid in vitro assay for quantitating the invasive potential of tumor cells. Cancer Res 1987, 47(12):3239-3245.

16. Kawajiri H, Yashiro M, Shinto O, Nakamura K, Tendo M, Takemura S, Node M, Hamashima Y, Kajimoto T, Sawada T, et al: A novel transforming growth factor beta receptor kinase inhibitor, $A-77$, prevents the peritoneal dissemination of scirrhous gastric carcinoma. Clin Cancer Res 2008, 14(9):2850-2860.

17. Zhang X, Yashiro M, Ohira M, Ren J, Hirakawa K: Synergic antiproliferative effect of DNA methyltransferase inhibitor in combination with anticancer drugs in gastric carcinoma. Cancer Sci 2006, 97(9):938-944.

18. Metlapally R, Jobling Al, Gentle A, McBrien NA: Characterization of the integrin receptor subunit profile in the mammalian sclera. Mol Vis 2006, 12:725-734

19. Kim SY, Kim DH, Han SJ, Hyun JW, Kim HS: Repression of matrix metalloproteinase gene expression by ginsenoside Rh2 in human astroglioma cells. Biochem Pharmacol 2007, 74(11):1642-1651.

20. Singh AP, Moniaux N, Chauhan SC, Meza JL, Batra SK: Inhibition of MUC4 expression suppresses pancreatic tumor cell growth and metastasis. Cancer Res 2004, 64(2):622-630.

21. Lohi J: Laminin-5 in the progression of carcinomas. Int J Cancer 2001 94(6):763-767.

22. Gupta SK, Vlahakis NE: Integrin \{alpha\}9\{beta\}1 mediates enhanced cell migration through nitric oxide synthase activity regulated by Src tyrosine kinase. J Cell Sci 2009, 122(Pt 12):2043-2054.

23. Hosotani R, Kawaguchi M, Masui T, Koshiba T, Ida J, Fujimoto K, Wada M, Doi R, Imamura M: Expression of integrin alphaVbeta3 in pancreatic carcinoma: relation to MMP-2 activation and lymph node metastasis. Pancreas 2002, 25(2):e30-35.

24. Mercapide J, Lopez De Cicco R, Castresana JS, Klein-Szanto AJ: Stromelysin-1/matrix metalloproteinase-3 (MMP-3) expression accounts for invasive properties of human astrocytoma cell lines. Int J Cancer 2003, 106(5):676-682

25. Korc M: Pathways for aberrant angiogenesis in pancreatic cancer. $\mathrm{Mo}$ Cancer 2003, 2:8.

26. Robinson CJ, Stringer SE: The splice variants of vascular endothelial growth factor (VEGF) and their receptors. J Cell Sci 2001, 114(Pt 5):853-865.

27. Seo Y, Baba H, Fukuda T, Takashima M, Sugimachi K: High expression of vascular endothelial growth factor is associated with liver metastasis and a poor prognosis for patients with ductal pancreatic adenocarcinoma. Cancer 2000, 88(10):2239-2245.

28. Luo J, Guo P, Matsuda K, Truong N, Lee A, Chun C, Cheng SY, Korc M: Pancreatic cancer cell-derived vascular endothelial growth factor is biologically active in vitro and enhances tumorigenicity in vivo. Int $\mathrm{J}$ Cancer 2001, 92(3):361-369.

29. Lu KH, Patterson AP, Wang L, Marquez RT, Atkinson EN, Baggerly KA, Ramoth LR, Rosen DG, Liu J, Hellstrom I, et al:: Selection of potential markers for epithelial ovarian cancer with gene expression arrays and recursive descent partition analysis. Clin Cancer Res 2004, 10(10):3291-3300

30. Giatromanolaki A, Koukourakis MI, Sivridis E, O'Byrne K, Cox G, Thorpe PE Gatter KC, Harris AL: Coexpression of MUC1 glycoprotein with multiple angiogenic factors in non-small cell lung cancer suggests coactivation of angiogenic and migration pathways. Clin Cancer Res 2000, 6(5):1917-1921

31. Heo SH, Choi YJ, Ryoo HM, Cho JY: Expression profiling of ETS and MMP factors in VEGF-activated endothelial cells: Role of MMP-10 in VEGFinduced angiogenesis. Journal of cellular physiology 2010 in press. 
32. Wey JS, Fan F, Gray MJ, Bauer TW, McCarty MF, Somcio R, Liu W, Evans DB, Wu Y, Hicklin DJ, et al: Vascular endothelial growth factor receptor-1 promotes migration and invasion in pancreatic carcinoma cell lines. Cancer 2005, 104(2):427-438

33. Itakura J, Ishiwata T, Friess H, Fujii H, Matsumoto Y, Buchler MW, Korc M: Enhanced expression of vascular endothelial growth factor in human pancreatic cancer correlates with local disease progression. Clin Cancer Res 1997, 3(8):1309-1316.

34. Ikeda N, Adachi M, Taki T, Huang C, Hashida H, Takabayashi A, Sho M, Nakajima Y, Kanehiro H, Hisanaga M, et al:: Prognostic significance of angiogenesis in human pancreatic cancer. Br J Cancer 1999, 79(910):1553-1563.

35. Fukasawa M, Korc M: Vascular endothelial growth factor-trap suppresses tumorigenicity of multiple pancreatic cancer cell lines. Clin Cancer Res 2004, 10(10):3327-3332.

doi: 10.1186/1756-9966-29-53

Cite this article as: Yamazoe et al., RNA interference suppression of mucin $5 A C$ (MUC5AC) reduces the adhesive and invasive capacity of human pancreatic cancer cells Journal of Experimental \& Clinical Cancer Research 2010, 29:53

Submit your next manuscript to BioMed Central and take full advantage of:

- Convenient online submission

- Thorough peer review

- No space constraints or color figure charges

- Immediate publication on acceptance

- Inclusion in PubMed, CAS, Scopus and Google Scholar

- Research which is freely available for redistribution

Submit your manuscript at www.biomedcentral.com/submit
C) Biomed Central 